\title{
Editorial
}

\section{Ecologically Oriented Sustainable Development of Gas Industry in Polar Regions of Russia: Environment-economy-management}

\author{
Vladimir N. Bashkin* \\ Institute of Physicochemical and Biological Problems of Soil Science RAS, Pushchino, Moscow Region, 142292 Russia \\ and Institute of Natural Gases and Gas Technologies - Gazprom VNIIGAZ LLC, Razvilka, Leninsky District, Moscow \\ Region, 142719 Russia
}

\section{ECOLOGICAL IMPERATIVE AS A BASIS FOR SUS- TAINABLE GAS INDUSTRY DEVELOPMENT IN POLAR REGIONS}

In this issue of OEJ the concept of ecologically oriented gas industry sustainable development in the Polar Regions of Russia is considered on the basis of ecological imperatives including ecological indicators of impacted ecosystems in severe climatic conditions, assessing (geo)ecological risks and ecologically oriented management.

The authors give an outline of the present-day natural gas production and its prospects in Polar Regions of Russia, explores how to identify (geo)ecolgical risks that may occur at various production stages and lead to emergency situations, and proposes strategies for accident prevention and postaccident remediation activities. The final papers focus on the approaches to (geo)ecological and regional risk management at Gazprom Dobycha Yamburg LLC, the main Gazprom production subsidiary.

Gas industry is considered to be an important sector of the fuel and energy complex of the Russian Federation encompassing exploration and development of natural gas fields, gas processing into marketable products, gas underground storaging and transmission by trunk pipelines, supply of commercial gas along with gasochemical resources to various industrial, housing and utilities sectors for further use as a source of energy and feedstock (Russian Encyclopedia of Gas 2004). Gas industry is viewed as a backbone of the economy. Its sustainable development has a significant effect on the positive development of the overall industrial production and the society in general. So, unlike the majority of other economic sectors the distinctive feature of gas industry is that it incorporates all the elements of the value chain, from production to consumption, including reserves increment, gas production, transmission, storage, processing,

\footnotetext{
*Address correspondence to this author at the Institute of Physicochemical and Biological Problems of soil Science RAS: Prof., Dr (biol) Vladimir Bashkin, Principal Researcher, Pushchino, Moscow region, 142292 Russia; Tel: +7 916 860-2038; Fax: +7 4967 33-0595;

E-mail: Bashkin@issp.serpukhov.su
}

export and distribution within the country. All these require stringent systemic planning of gas industry sustainable development that involves a joint analysis and coordinated forecast of synchronous and harmonious development for all the subsystems of gas industry (Samsonov et al. 2007; Sustainable... 2013).

Gas industry sustainable development is based on a wellknown Sustainable Development Concept which emerged as a result of three constituent parts integration: concepts of economic sustainability, social sustainability and environmental sustainability [http://ru.wikipedia.org/wiki/Sustainable Development].

Being now well-adopted and recognizable, Sustainable Development is a broad and interdisciplinary field with many niche areas (Fig. 1). The concept of Sustainable development was first articulated when the UN World Commission on Environment and Development (Brundtland Commission) published its "Our Common Future" report in 1987. In this report, Sustainable Development was defined as:

...development which meets the needs of current generations without compromising the ability of future generations to meet their own needs.

Since that time, there has been a great deal of debate on exactly what Sustainable Development is and how it should be implemented. However, despite this debate this concept has often blurred the lines artificially drawn between disciplines and ideologies, and has brought stakeholders across a wide spectrum together to discuss our current path of development and the future of our society and its place within nature.

Economic sustainability concept stems from the HicksLindahl concept of the maximum income that could be generated while at least retaining the stock of assets (or capital) to derive these benefits. Social sustainability concept focuses on human life and implies stability of social and cultural systems and equitable distribution of benefits. Environmental sustainability concept presupposes integrity of ecosystems and maintains their capacity for self-restoring and dynamic adjustment to changes that on the whole define stability of the global biosphere. 


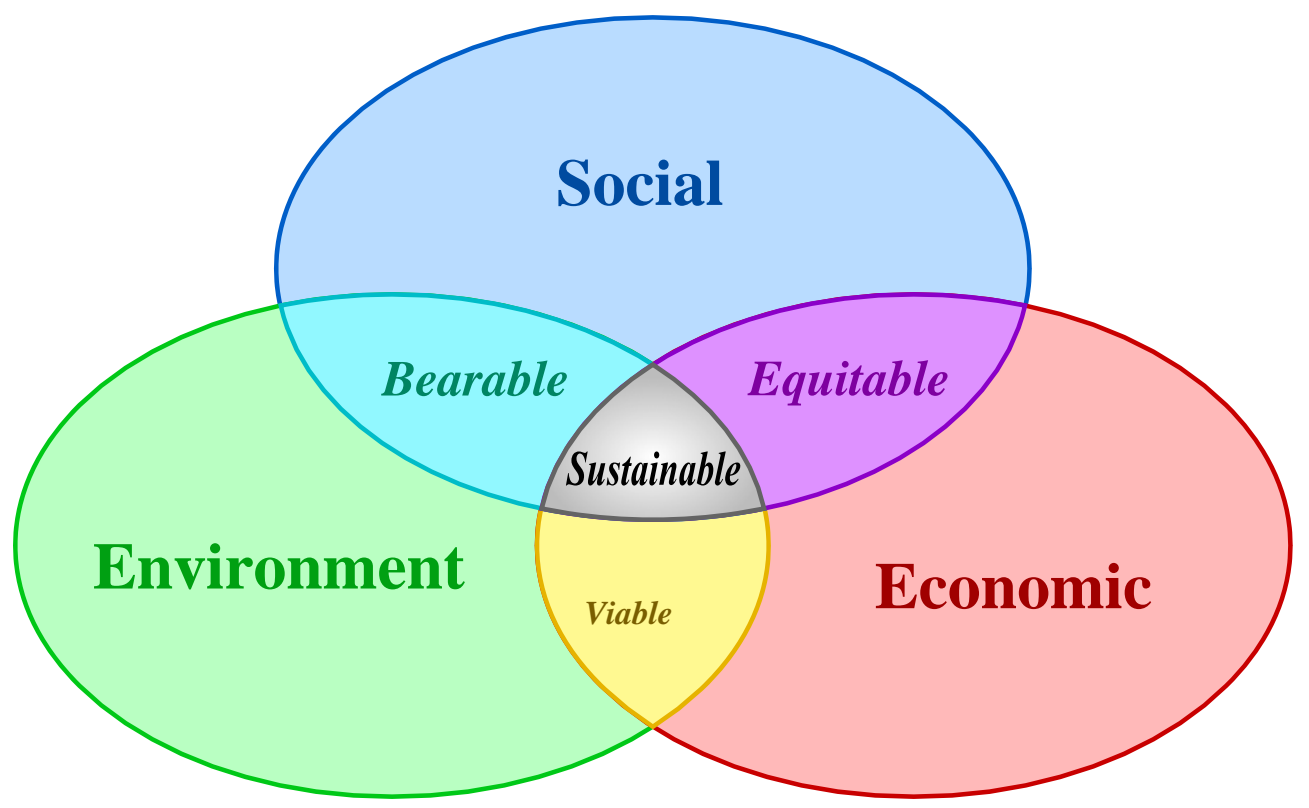

Fig. (1). General scheme of sustainable development.

The underlying factor of ensuring gas industry sustainable development is to work out a strategy covering methodological, geo-information, and economic and environmental aspects. In this context, it is essential to describe gas industry as a specific economic sector, current and future gas production status in conjunction with the logistics system based on the 'production - transmission - market' chain. Objective prospects for sustainable development of gas industry and natural gas as a source of energy supplied to the market may be fairly assessed only by comparison with the alternative energy sources. The same applies to geoecological risks assessment and risk management at OAO Gazprom, which is the leading Russian national corporation controlling one third of the globally developed gas reserves and $60 \%$ of those in Russia (Russian Encyclopedia of Gas, 2004; World Energy Outlook 2014).

The determining factor of gas industry sustainable development is formulation of its strategy as an art of management, which is based on long-term forecasts. This goal may be attained via relevant methodology and systemic analysis. Sustainable development strategy cannot be developed without:

- methodology of its formulation;

- introduction of geo-information systems;

- assessment of its cost-effectiveness;

- philosophy of managing systemic risks as multistage iteration process;

- assessment of systemic risks and their management as a multi-variant iterative process;

- different risks assessment and management with regard to multi-variant development of the gas industry;

- identification of geo-environmental risks as a result of 'gas industry - environment' system interaction .
At present Gazprom JSC as the leading national company and one of the largest global corporations gives an insight into natural gas production through the performance of its four key subsidiaries in Western Siberia. The prospects of gas production as one of the cornerstones of global energy balance for the period of 2030-2035 are viewed from the perspective of Western and Eastern Siberia and the Far East. At the same time the future of gas industry in Russia depends on the pace of exploration activity and fields commissioning onshore and off-shore in the Arctic and Far East seas. Logistics mechanisms of gas industry are clearly seen in gas transmission system as a link of 'productiontransmission-market' chain. Trends of natural gas markets development in the Russian Federation are determined by infrastructure, competitive environment, price parameters and consumption patterns.

As to gas and alternative energy context, hydrogen energy tends to be one of the most appealing resources for the country's fuel and energy sector since natural gas today is the main source of hydrogen. Moreover, the technology of hydrogen energy production allows gas industry to tackle the problem of marginal wells and establish its own energy supply systems strongly needed now as the remote areas of the Far North and the Arctic seas shelves are being developed. Natural gas in compressed or liquefied state may serve as an efficient substitute for conventional fuels as it is environmentally friendly, energy intensive and have low cost. Gas industry sustainable development is not possible without simultaneous management of geo-environmental risks that arise at different stages of production in the form of environmental emissions or spills of various chemical substances in extremely large amounts, which are highly hazardous for people. In order to prevent human exposure to these substances, it is of primary importance to ensure preventive maintenance and remediation of implications. 
It is well-known that the Russian Federation accumulates the major natural gas reserves and the largest part of these reserves is located in Polar Regions with severe natural conditions and vulnerable environment. Monetization of these reserves and gas supplies to both domestic and foreign consumers require using sustainable development approaches based on unified environmental, social and economic principles. These principles should be the grounds for industrial activity of all gas companies. The industrial activity, including natural gas production and transmission, of the leading global and Russian company, Gazprom, is based on these sustainable development principles. Gazprom Dobycha Yamburg, which operates in the arctic conditions, is one of Gazprom's most successful and environmentally focused subsidiary companies.

Gazprom Dobycha Yamburg pursues the sustainable development policy in all industrial areas, which is confirmed by statistical information submitted in the company's reports. It has been shown that sustainable development principles should be used to meet contemporary technical and management regulations. Fields developed by Gazprom Dobycha Yamburg are located under severe natural, climatic and geoecological conditions. Sustainable development under these conditions should meet a range of criteria used in the international practice. Continuous improvement of gas industry operation is vital for moving the world to sustainable energy system of the future. This point is included into reports of the International Gas Union. It has been shown that power industry based on gas is the most pure and environmentally friendly both on the regional and global level. Gazprom Dobycha Yamburg LLC is a perfect example of successful geo-environmental risks management in gas industry. The Company's policy in the sphere of environmental protection is based on the concept of gas industry sustainable development and is targeted at the stringent compliance with the Russian environmental laws and international ecological standards. The policy comprises a series of sequential efforts to be taken as well as R\&D activities. So, it may be stated that the long-term experience of the Company in the sphere of gas industry sustainable development proves to be relevant and appropriate for replication by other Gazprom JSC subsidiaries developing hydrocarbon fields in the Far North.

This issue will be the basis for estimating company's sustainable development, organization of management systems and environmental monitoring and assessment of acceptable impact on polar ecosystems. It will be useful for many readers, and will show environmental, social and economic practice of gas industry operation based on sustainable development principles.

\section{CONFLICT OF INTEREST}

The author confirms that this article content has no conflict of interest.

\section{ACKNOWLEDGMENTS}

The papers for this issue of Open Ecological Journal have been prepared by researchers from different companies such as OAO Gazprom, Gazprom Dobycha Yamburg LLC, Gazprom VNIIGAZ LLC, NIIGazeconomica LLC, Institute of Physicochemical and Biological Problems in Soil Science, Institute of Soil Science and Agrochemistry and Institute of Fundamental Problems of Biology of the Russian Academy of Sciences, M.V. Lononosov Federal Polar University and Guest Editor of this issue expresses its deep appreciation and gratitude to the relevant companies and research institutions for support.

\section{REFERENCES}

http://ru.wikipedia.org/wiki/Sustainable Development Russian Gas Encyclopedia (2004), Great Russian Encyclopedia, Moscow. Samsonov, RO, Kazak, AS \& Bashkin, VN (2007) Master plan methodology for gas industry development, scientific world, Moscow. Sustainable development of gas industry (2013) Nedra, Moscow.

World Energy Outlook 2014. http://www.worldenergyoutlook.org/ World Energy Outlook 2014 